\title{
Canadians want seniors care plan
}

$\mathrm{N}$ ine in 10 Canadians want a national strategy for seniors' care, and most expect federal leadership on the issue, a Canadian Medical Association (CMA) survey reveals.

According to the CMA's 15th Annual National Report Card on Health Care, $76 \%$ of Canadians say governments should cooperate closely to develop a national strategy, and $67 \%$ agree the federal government has an important role in that process. More than half $(57 \%)$ say their vote in the upcoming federal election will be influenced by who has the best plan to tackle seniors' issues, including health care.

"It completely sets aside any notion that the federal government has no role in health care; Canadians clearly believe they do," says CMA President Dr. Chris Simpson. "Stat-

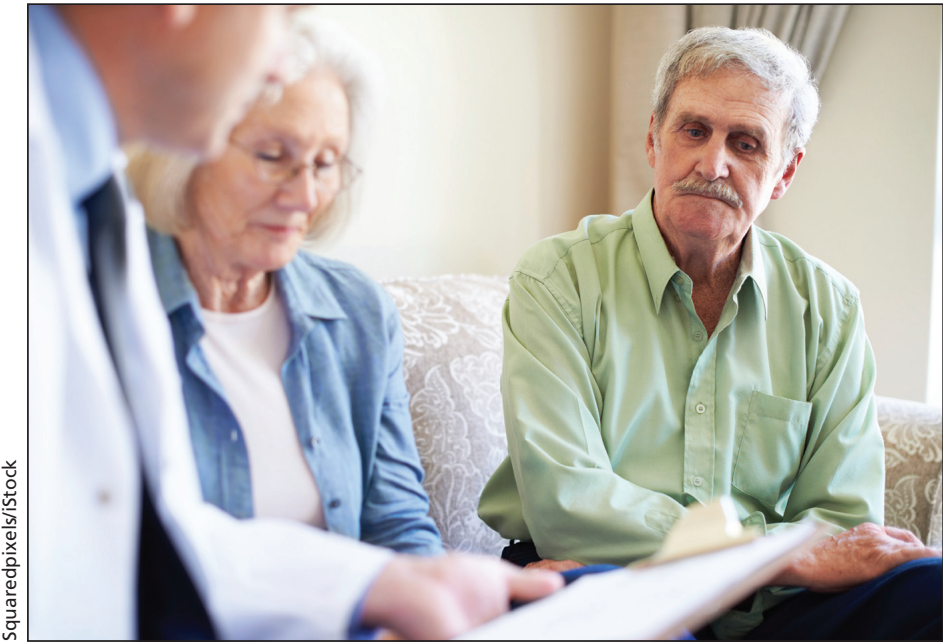

Canadians want a national seniors care plan to bolster training for health workers, and access to home care and long-term care. say their families are not in a good position to care for elderly members, and it worries them greatly.

Simpson says it's telling that female respondents and those aged 55 to 64 express the most anxiety. "Women are more frequently called on to be caregivers," he explains. Meanwhile, "the

resources plan since the 70 s, " he notes. "In a country where people move around, isolated approaches don't really work."

Most respondents $(72 \%)$ were also receptive to the idea of giving provinces with a higher proportion of seniors more federal money to deal with that age cohort's higher health costs. Starting in 2017, the federal government will cap growth in provincial health transfers at $3 \%$, or Canada's gross domestic product growth. These funds are distributed on a per capita basis. CMA is proposing the government restore a $6 \%$ annual increase, "but that additional $3 \%$ would be allocated on the basis of demographics," explains Simpson. "In absolute terms, every province would get more money, but the ones with more seniors would get a greater proportion of the increase."

Support for the notion of redistribut-

upcoming baby boomer generation simply doesn't tolerate uncoordinated care and poor service." improve things is not the leadership that we need."

The CMA commissioned Ipsos Reid to survey 2008 Canadian adults in July 2015. The results are accurate within \pm 2.5 percentage points, 19 times of 20 .

Although $69 \%$ of respondents to CMA's survey give an A or B grade to the overall health services available to them, just $49 \%$ assign the same grade when it comes to services for seniors. Fewer still are confident that hospitals in their area can handle the needs of the elderly population $(33 \%)$, or that there are enough long-term care facilities (24\%) or home-care services $(24 \%)$.

These shortfalls leave many people facing the challenging prospect of caring for an older family member themselves. Three in five Canadians (63\%)

\section{Doctors' training a top priority}

Respondents to CMA's survey were most concerned about building capacity in the health system to meet seniors' needs. Ninety-two percent said ensuring enough health professionals are trained to provide seniors' care is a priority, followed by providing long-term home care $(89 \%)$ and increasing access to long-term care facilities $(88 \%)$.

"We don't need to get into too much high-tech stuff, although that's often the way people think about health care innovation," says Simpson. The results also reflect the fact that core medical training "may not be enough to look after the complexities that we often see in older age," he says. Meanwhile, "we haven't had a national health human ing federal funds is fairly consistent across the country, according to CMA's survey, with the exception of Alberta, where it drops to 61\%. Possibly, this reflects Alberta's younger population, says Simpson.

The idea also appears to be gaining traction with politicians. Quebec, New Brunswick and Saskatchewan's premiers support the idea, while the federal New Democrats, Liberals and Greens have "all alluded to the fact they're sympathetic," say Simpson. "We know the NDP is on record saying they would restore the $6 \%$ escalator although they haven't explicitly said that would be according to demographics."

Seniors' care will also be a focus at the CMA's annual general council in Halifax this week. - Lauren Vogel, CMAJ

CMAJ 2015. DOI:10.1503/cmaj.109-5134 